\title{
PANORAMA DOS ESTUDOS SOBRE ADAPTAÇÃO ÀS MUDANÇAS CLIMÁTICAS GLOBAIS ENTRE 1999 E 2013 POR MEIO DA ANÁLISE DA REVISTA "MITIGATION AND ADAPTATION STRATEGIES FOR GLOBAL CHANGE"
}

\author{
MOREIRA, Fabiano de Araujo - fabianoamoreira@yahoo.com.br \\ Universidade Estadual de Campinas / UNICAMP \\ NUNES, Luci Hidalgo - luci@ige.unicamp.br \\ Universidade Estadual de Campinas / UNICAMP
}

\begin{abstract}
RESUMO: A evolução da pesquisa em adaptação é avaliada tendo como estudo de caso as publicações em uma revista de maneira a observar o aumento do número de estudos em adaptação e sua representatividade nos países. A escolha recaiu na publicação Mitigation and Adaptation Strategies for Global Change e os períodos definidos para análise foram de 1999-2003 e 2009-2013. Observou-se que o número de artigos em adaptação nessa revista passou de 23 no primeiro período para 118 no segundo, enquanto os demais temas passaram de 80 para 130 artigos, demonstrando significativo aumento das pesquisas publicadas nessa revista abordando questões de adaptação, quase se igualando às demais temáticas. Esse incremento se deu principalmente após o Acordo de Marrakesh (COP de 2001, adotado em 2005), que criou um fundo para financiar a adaptação, assim como a necessidade de serem discutidas outras ações para enfrentamento das mudanças climáticas globais em um cenário em que a mitigação era o principal foco. Estudos dos cinco continentes foram contemplados pela revista, porém, com maior ênfase para países centrais, da América do Norte e Europa. Parcerias internacionais para financiamento de pesquisas tiveram destaque, demonstrando a importância dessas relações para o desenvolvimento de estudos em países que carecem de recursos. Os resultados apontam para a importância da correlação entre mitigação e adaptação, que devem ser desenvolvidas em conjunto.
\end{abstract}

Palavras- chaves: Adaptação; Mitigação; Mudanças climáticas; IPCC; Capacidade Adaptativa.

AN OVERVIEW OF STUDIES ON ADAPTATION TO GLOBAL CLIMATE CHANGE BETWEEN 1999 AND 2013 THROUGH AN ANALYSIS OF "MITIGATION AND ADAPTATION STRATEGIES FOR GLOBAL CHANGE"

\begin{abstract}
The evolution of climate change adaptation research is evaluated based on publications from Mitigation and Adaptation Strategies for Global Change journal, which were analysed between 1999 and 2003 and between 2009 and 2013, to observe the trends of studies on adaptation in both periods. We observed that the number of papers on adaptation in this journal went from 23 in the first period to 118 in the second one, whereas the remaining topics shifter from 80 to 130 articles, which demonstrates a significant increase in the number of studies on adaptation policies, which were almost as numerous as the remaining topics. This increase mainly took place after the Marrakech Agreement (2001 COP, adopted in 2005), which created a fund to finance adaptation, thus showing the need to discuss other initiatives to tackle global climate change in a scenario in which mitigation was the main focus. We noticed there were studies in the five continents, with more emphasis to North American and European countries, though. International research funding partnerships were highlighted, which demonstrated the importance of these relationships in the conduction of studies in underprivileged countries. The results pointed towards the importance of correlating mitigation and adaptation, which must be conducted together.
\end{abstract}

Keywords: Adaptation; Mitigation; Climate Change; IPCC; Adaptive Capacity 


\section{INTRODUÇÃO}

Existem duas formas de enfrentar os possíveis efeitos das mudanças climáticas: a mitigação e a adaptação. A mitigação relaciona-se às medidas para reduzir as emissões e aumentar a absorção dos gases de efeito estufa, enquanto a adaptação se refere às medidas de preparo para os efeitos adversos provenientes das mudanças do clima. Conforme explica Mimura (2010), inicialmente foram realizados inúmeros esforços no sentido de mitigar as emissões dos gases de efeito estufa, principalmente pelos países desenvolvidos e industrializados; porém, com a crescente preocupação de diversos países sobre os impactos que essas mudanças podem causar em seus territórios, passa a ser reconhecida a necessidade e a importância das medidas adaptativas.

A previsão sobre o aquecimento global é de que nas próximas décadas a temperatura aumente em torno de $0,2^{\circ} \mathrm{C}$ por década até 2030 , independente da redução da emissão dos gases. Isso significa que os gases já existentes permanecerão na atmosfera por várias décadas, causando esse aquecimento pelos próximos 20-30 anos. Ou seja: a atmosfera já se encontra em estado de inércia para o aquecimento global. Isso não significa que não exista a necessidade de realizar medidas de mitigação; pelo contrário: reduzir as emissões nos dias atuais tem efeito decisivo no futuro do aquecimento global em longo prazo, já que o período de permanência dos gases de efeito estufa na atmosfera é de, aproximadamente, 70 anos. Atrasar em 30 anos a redução desses gases poderia significar um atraso na estabilização da emissão desses gases e, assim, na aceleração do aquecimento global (MIMURA, 2010).

Com esse cenário em vista, sabe-se que as medidas de mitigação devem continuar a ser estimuladas; entretanto, não se devem deixar de lado as medidas de adaptação devido a sua importância pelas próximas décadas, enquanto as emissões dos gases de efeito estufa não são estabilizadas e, consequentemente, o aquecimento global continua a acontecer e seus efeitos podem começar a ser sentidos. Caso esse cenário se concretize, as pessoas em todo o globo podem começar a sentir os efeitos desse aquecimento, com risco maior aos países em desenvolvimento, onde há menores condições para se preparar para os impactos de diversas naturezas associados a essa situação. Sendo assim, as duas medidas de resposta às mudanças climáticas devem ser trabalhadas em conjunto e não separadas como anteriormente (MIMURA, 2010).

O aumento das pesquisas sobre adaptação segue essa tendência em discutir os dois movimentos no cenário internacional, após um período em que o destaque era todo para a mitigação. De acordo com o Painel Intergovernamental sobre Mudanças Climáticas (IPCC, 2014), após meados da década de 2000 houve significativo crescimento do número de artigos publicados em todo o mundo sobre adaptação, impactos e custos, mais do que dobrando o número de publicações prévias, como visualizado na Figura 1.

Segundo o IPCC (2014), o crescimento recente da literatura sobre as mudanças climáticas, principalmente aquela que se refere aos impactos e à adaptação, teve influência significativa no alcance e na profundidade dos relatórios produzidos pelo IPCC e resultaram em enorme avanço nas avaliações de impactos, vulnerabilidades e políticas adaptativas. Já é possível observar que o crescimento da literatura e experiência sobre adaptação na última década 
possibilitou o desenvolvimento de inúmeras políticas nesse sentido em diversas partes do mundo.

A análise dos documentos e publicações realizadas até 2004 indicam a prevalência da mitigação sobre os outros tópicos das mudanças do clima. Contudo, conforme vislumbrado no $5^{\circ}$ relatório do IPCC (2014), as pesquisas em adaptação têm tido destaque em países da América Latina e em convenções de países não-Anexo 1, como Índia e Irã, os quais dedicaram boa parte de seus relatórios para a adaptação. Alguns pesquisadores e instituições passaram a identificar as possibilidades para o desenvolvimento de medidas adaptativas e financiamento, procurando as melhores maneiras para haver um benefício mútuo entre essas medidas e as de mitigação.

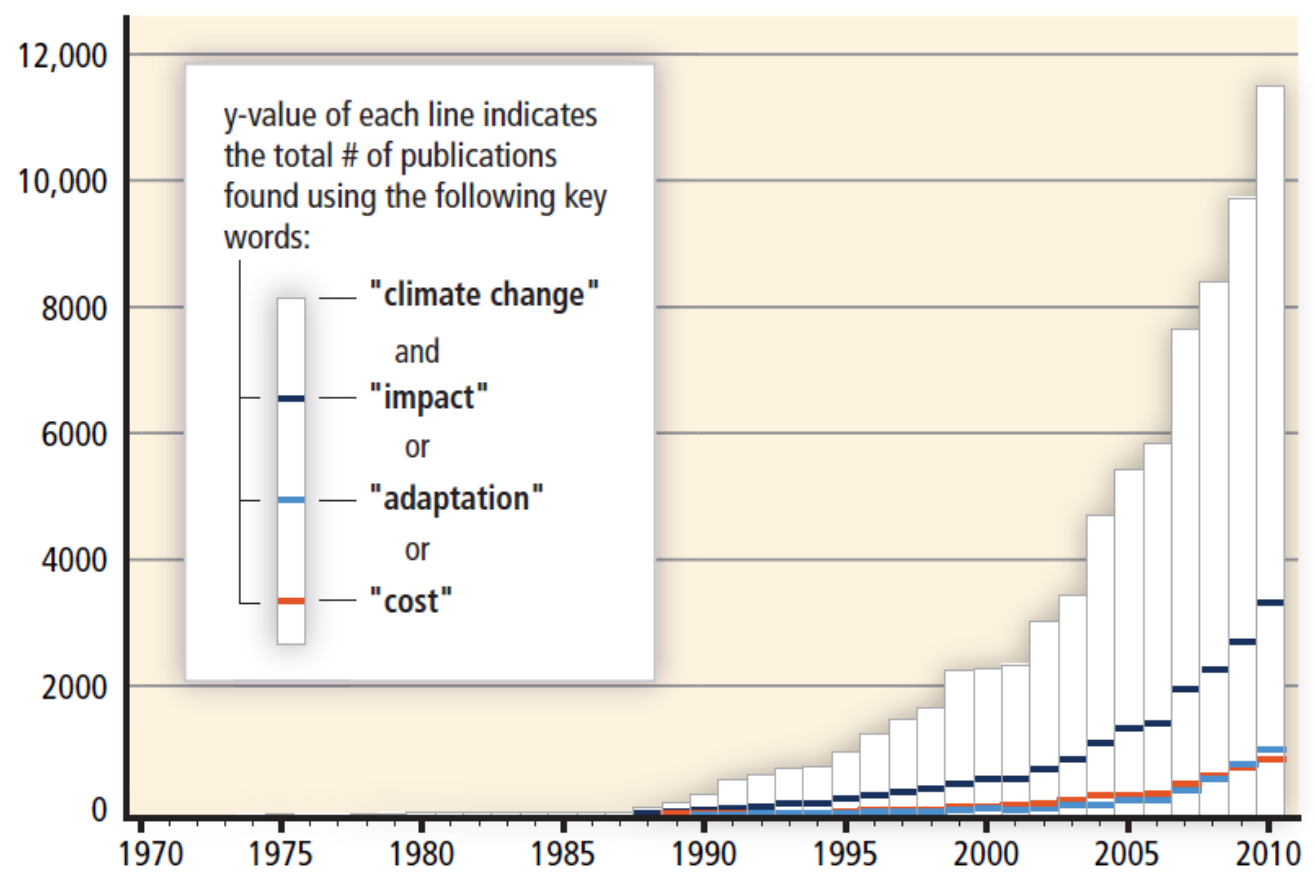

Figura 1 - Crescimento do número de artigos sobre mudanças climáticas (1970-2010) Fonte: IPCC (2014).

Seguindo essa linha, este artigo pretende analisar a evolução da pesquisa em adaptação, reconhecendo os desdobramentos dos encontros internacionais sobre o tema e como a adaptação surgiu, em meados da década de 2000, como opção aos esforços de mitigação apresentados até então.

Com esse objetivo, foi selecionada uma revista internacional de destaque no meio, a Mitigation and Adaptation Strategies for Global Change, da editora Springer, pela qual se pôde observar a quantidade de publicações sobre adaptação e mitigação em dois períodos, 1999-2003 e 2009-2013, possibilitando uma análise quantitativa e qualitativa dos temas abordados inseridos na temática de adaptação no período em que houve uma mudança de perspectiva, quando a mitigação passou a partilhar as atenções dos pesquisadores com outros temas. A pesquisa também avaliou a distribuição global dos artigos sobre o tema, fornecendo um panorama dos países que mais 
publicam, de onde surgem os financiamentos para as pesquisas, quais áreas de conhecimento atuam nessas questões e a importância das parcerias internacionais para o desenvolvimento de estudos nos países em desenvolvimento.

Destaca-se, ainda, que avaliar a evolução da ciência apresenta inúmeros benefícios, como identificação das mudanças de perspectiva de certo setor ao longo do tempo, de áreas (científicas e geográficas) que necessitam maior ênfase e dos campos científicos que contribuem para o entendimento de uma dada perspectiva, entre outros aspectos. Várias áreas têm merecido essa atenção, como atestam os estudos de Skaggs (2004), Oreskes (2004) e Heller e Zavaleta (2009).

Essa pesquisa se insere no contexto do projeto temático Metropole (chamada Forum Belmont), que visa contribuir para a articulação entre os cenários projetados por pesquisas científicas sobre as mudanças climáticas e as decisões políticas sobre adaptação de municípios dos três países integrantes do projeto: EUA, Reino Unido e Brasil, sendo esse artigo essencial para a compreensão do pensamento atual sobre adaptação, que é o alicerce do projeto temático.

\section{ADAPTAÇÃO}

A adaptação pode contribuir significativamente com a redução dos riscos dos impactos das mudanças climáticas, melhorando o bem-estar da população, a segurança de seus bens e a manutenção dos ecossistemas, bem como contribui para o planejamento dos locais que possam ser afetados. Em uma perspectiva de longo prazo, em um contexto de desenvolvimento sustentável, ações imediatas de adaptação também podem significar aumento nas chances de melhores opções de adaptação no futuro, destacando a importância de medidas imediatas para o enfrentamento dos efeitos futuros das mudanças no clima (IPCC, 2014).

No estudo de mitigação e adaptação às mudanças climáticas, além da avaliação das possíveis respostas no âmbito dos governos nacionais e organizações internacionais, outra contribuição se coaduna à análise das respostas das sociedades passadas diante das mudanças ambientais, inclusive climáticas. Quanto a isso, vale lembrar que a adaptação às transformações ambientais, em especial, às mudanças do clima, constitui-se parte integrante da história da humanidade, sendo que no passado algumas sociedades que não conseguiram se adaptar às novas condições, entraram em colapso: foi o caso da população polinésia que habitava a Ilha de Páscoa, pois o enorme desmatamento promovido pela população, além de inviabilizar a construção de canoas para as atividades de pesca, promoveu extensiva erosão, impactando também a agricultura com a redução dos campos agricultáveis (ORLOVE, 2005).

Outras sociedades desenvolveram formas de adaptação às condições locais: no caso dos indígenas da Amazônia, por exemplo, as palafitas revelam a forte relação dos residentes com o seu espaço e com o papel central dos rios nas tradições dos povos. Nos Países Baixos, as soluções adaptativas constituemse em aspecto indissociável dessa nação, que tem 1/4 das terras abaixo do nível do mar, protegidas por diques ou drenadas por meio de canais. 
O 40 relatório do IPCC (2007) apresenta uma lista com diversas medidas de adaptação recentes em diferentes locais do mundo, que incluem medidas contra a seca (expansão do uso de águas da chuva para as culturas, monitoramento do número de animais e de árvores cortadas, assistência à agricultura de subsistência, mudanças para culturas mais resistentes), relativas à elevação do nível do mar (regulamentar distâncias para as infraestruturas costeiras, introdução de avaliação de risco com natureza participatória, construção de unidades habitacionais resilientes aos ciclones, construção de barreiras) e aos extremos de temperatura (implementação de planos de alerta a ondas de calor, distribuição de água para populações vulneráveis), entre outros (IPCC, 2007).

De acordo com o $5^{\circ}$ relatório do IPCC (2014), o primeiro passo para uma adaptação frente às mudanças no clima seria a redução de vulnerabilidades e de exposição às variabilidades climáticas atuais. A integração de opções de adaptação em ações de planejamento, por meio de formulação de políticas púbicas, pode promover sinergias entre o desenvolvimento e a redução do risco de desastres, ao mesmo tempo em que a construção de capacidade adaptativa se mostra crucial para a seleção e implementação das opções adaptativas essenciais para cada caso.

O planejamento e a implementação de medidas de adaptação podem ser aprimorados por meio de ações complementares em diversos níveis, partindo desde os próprios indivíduos em situação de risco até os governantes. Pela revista analisada, alguns artigos se destacam sobre implementação e melhoria de medidas adaptativas pelas populações locais ou pelos governantes, como: "Paddy farmers' adaptation practices to climatic vulnerabilities in Malaysia" (ALAM et al. 2012) e "The role of uncertainty in climate change adaptation strategies - A Danish water management example" (REFSGAARD et al. 2013).

Os governos nacionais podem coordenar os esforços de adaptação local por meio de, por exemplo, proteção às populações vulneráveis, suporte financeiro aos projetos de adaptação e fornecimento de informações, políticas e quadros legais, enquanto os governos locais e o setor privado obtêm cada vez mais reconhecimento como atores centrais para a evolução dessa questão devido a seu papel fundamental em ampliar a adaptação das comunidades e no gerenciamento de informações sobre os riscos locais (IPCC, 2014).

Outro fator imprescindível na busca de melhores opções de medidas adaptativas, consoante com o IPCC (2014), é o reconhecimento dos valores sociais e percepções de risco presentes nas comunidades, e isso ocorre por meio da caracterização dos diversos interesses, circunstâncias, contextos socioculturais e expectativas dessas populações vulneráveis. Sendo assim, os conhecimentos locais e tradicionais como, por exemplo, a visão holística dos indígenas sobre comunidades e meio ambiente, são recursos primordiais para a formulação de medidas de adaptação efetivas. Entretanto, até o momento, pouca atenção foi dada sobre essa questão, sendo necessária, cada vez mais, uma integração entre tais formas de conhecimento local e as ações de planejamento para adaptações futuras. Como explica Ferreira (2003), as discussões sobre mudanças climáticas até o início da década de 2000 pareciam repetir o processo de políticas regulatórias de caráter meramente normativo, mas sem acompanhamento de políticas sociais, evidenciando a necessidade dessas ações nesses debates. 
Alguns percalços podem surgir nas ações de planejamento e implementação de ações de adaptação; entre eles, pode-se destacar a baixa integração e coordenação entre os governos; limitados recursos financeiros e humanos; incertezas sobre as previsões de impactos; diferentes percepções de risco; ausências de líderes que promovam essas ações; escassez de ferramentas para avaliar a efetividade das medidas adaptativas; entre outros (IPCC, 2014).

Os limites da adaptação também são motivos de preocupação. Embora sejam realizadas diversas medidas adaptativas seguindo determinadas previsões sobre as consequências possíveis das mudanças no clima, elas podem não ser suficientes, caso esses impactos sejam maiores do que as previsões anteriores. Além disso, como sustenta o IPCC (2014), um planejamento ou uma implementação mal feitos, a supervalorização de resultados em curto prazo ou a ineficácia na antecipação dos impactos possíveis podem resultar em má adaptação, aumentando a vulnerabilidade local e, até mesmo, impactando outros setores e populações que não eram vulneráveis anteriormente. Subestimar a complexidade de medidas adaptativas como um processo social pode criar expectativas irreais quanto às intenções iniciais do processo de adaptação.

Algumas medidas podem contribuir para promover a adaptação e mesmo o desenvolvimento nas sociedades, como é o caso das transformações econômicas, sociais, tecnológicas e nas tomadas de decisão e ações políticas. A realização de ações de adaptação restritas a melhorias de estruturas e sistemas já existentes, sem considerar as demais transformações necessárias, pode provocar aumento nos gastos e perdas de oportunidades (IPCC, 2014).

As medidas de adaptação estão sendo cada vez mais incorporadas nos processos de planejamento em algumas regiões, com reconhecimento crescente da necessidade da inclusão dos aspectos sociais, institucionais e ambientais nessas medidas. Tal prática faz com que haja maior acúmulo de experiência nesse campo, permitindo avanço cada vez mais significativo das medidas adaptativas para todos os setores (IPCC, 2014).

Apesar de uma maior atenção à adaptação, até os dias atuais a maioria dos estudos teve foco na mitigação. Todavia, é preciso compreender que não se podem dissociar as duas perspectivas e que, sendo assim, a adaptação e a mitigação devem ser consideradas medidas complementares. Conforme o IPCC (2014), uma redução efetiva nas emissões de gases de efeito estufa nas próximas décadas poderia reduzir os riscos provenientes das mudanças no clima, aumentar as probabilidades de obtenção de sucesso em medidas de adaptação, reduzir os gastos e desafios com a mitigação em longo prazo e contribuir com um cenário de desenvolvimento sustentável para a sociedade.

A diferença entre essas duas medidas complementares pode ser definida pela escala de tempo que abrangem. Enquanto a mitigação produz efeitos ao longo das décadas seguintes após suas medidas serem realizadas, podendo reduzir os resultados provenientes das mudanças no clima ao longo do século XXI, a adaptação tem efeito pouco após sua execução, para problemas já existentes em relação ao clima (IPCC, 2014).

Além disso, como explica Schipper (2009), existe diferença entre essas medidas sobre o foco que elas tomam: enquanto a mitigação enfatiza a fonte das mudanças climáticas, as ações de adaptação destacam suas consequências. 
Nesse sentido, quanto mais medidas de mitigação forem realizadas, menos adaptação será necessária, e vice-versa (SHIPPER, 2009; GRASSO, 2010). O problema entre essas duas ações reside em seus resultados, pois as ações de mitigação surtem efeito após um longo tempo de atuação à medida que, mesmo havendo redução das emissões de gases no presente, os gases já emitidos até então ainda permanecem na atmosfera por muitas décadas devido à inércia do sistema climático global; além disso, essa demora é intensificada pela lentidão na implementação de políticas efetivas de mitigação.

Na Convenção-Quadro das Nações Unidas sobre a Mudança do Clima (UNFCCC) houve grande destaque inicial à mitigação, deixando de lado a adaptação como resposta às mudanças climáticas antropogênicas, o que provocou uma dicotomia entre essas duas ações quanto às respostas mais efetivas para o enfrentamento das mudanças no clima. Enquanto a mitigação foi claramente definida na Convenção-Quadro, negociada em 1992, a adaptação não foi definida, embora esse termo tenha aparecido no texto final da Rio92 (PELLING, 2011).

Schipper (2009) assinala que houve consenso na comunidade científica de que as emissões de gases de efeito estufa deveriam ser freadas, e a UNFCCC foi a forma encontrada para se atingir tal objetivo, tendo o IPCC como apoio nas pesquisas, dando, também, foco inicial à mitigação, sendo superficial em relação à adaptação e vulnerabilidade.

Para Burton et al. (2009), a ideia inicial dos membros da UNFCCC, desde a Conferência das Partes de 1995 (COP1), era de que havia necessidade de se preparar para adaptação e só depois começar a avançar as discussões nesse sentido, sendo necessárias medidas de mitigação, inicialmente. Já segundo Schipper (2009), a falta de políticas sobre adaptação no período inicial das discussões sobre mudanças no clima foram vistas como uma estratégia política tomada pelos países desenvolvidos para evitar assumir alguma responsabilidade com consequentes gastos financeiros. Sendo assim, a UNFCCC priorizou as medidas para reduzir as fontes das mudanças climáticas em vez de se adaptar a elas. A capacidade adaptativa era vista como indicadora do quanto uma sociedade era capaz de tolerar uma mudança no clima, e não como um objetivo político.

Dessa maneira, nos anos iniciais das discussões sobre o clima na UNFCCC foi dado destaque ao Protocolo de Kyoto, com ênfase na mitigação. Suas regras foram estabelecidas posteriormente pelo Acordo de Marrakesh, que surgiu em 2001 e foi adotado em 2005. Na UNFCCC a adaptação se configurava na Decisão 11/CP.1 (COPI-1995) que, apesar de destinar um fundo para adaptação, não propôs explicitamente qualquer trabalho ou programa nesse sentido (SHIPPER, 2009). Sobre essa época, Ojima comenta que:

Embora a agenda das mudanças climáticas pareça ter entrado definitivamente nas pautas de discussão tanto da comunidade científica, como dos governos e da sociedade civil; na maior parte dos países, nem todos os aspectos têm sido tratados com a mesma atenção. Por um lado, a necessidade de ações de mitigação em relação às emissões de GEE [Gases de efeito estufa] já faz parte dos discursos de médio e longo prazo, entretanto, ainda há um vasto conjunto de dificuldades, 
incertezas e conflitos econômicos e políticos para efetiva integração dessas preocupações com a capacidade de adaptação que as diferentes regiões do mundo possuem (OJIMA, 2009, p.196).

Durante esse período, as medidas adaptativas emergiram como opções na discussão do enfrentamento aos efeitos provenientes das mudanças climáticas. Porém, conforme Schipper (2009), como as discussões sobre o Protocolo de Kyoto ainda avançavam, algumas barreiras ao desenvolvimento de ações de adaptação persistiam: incertezas científicas em relação às mudanças no clima, um grande foco em pesquisas sobre impactos em vez de medidas de adaptação e a falta de compreensão da necessidade prioritária de redução de vulnerabilidade. Além disso, havia uma ideia de que mudar o foco das discussões para a adaptação poderia enfraquecer os esforços empreendidos para a mitigação por parte dos países desenvolvidos.

Um dos argumentos utilizados para manter o foco das discussões na mitigação era o de que a humanidade, desde os primórdios, foi capaz de se adaptar, sendo assim, a adaptação às mudanças climáticas não era algo urgente como a redução das emissões dos gases de efeito estufa. Outro argumento era o de que dar atenção para a adaptação era uma ideia derrotista, que exigiria ajustes nos comportamentos humanos, assim como admitiria que as ações de mitigação não seriam eficazes, sendo também tida como não construtivas. Os céticos sobre as mudanças no clima também não facilitavam as discussões sobre adaptações, influenciados pelas incertezas científicas que geravam (e geram) grandes debates acerca do tema. Unindo-se a todos esses argumentos, era considerado perigoso para um país anunciar medidas de adaptação, pois isso era visto como se eles estivessem admitindo sua incapacidade de mitigação. Para além dos argumentos contrários aos processos de adaptação havia também a discussão sobre a criação de fundos para essas medidas, que remetiam à responsabilização pelas mudanças climáticas e compensações pelos danos causados, problemática essa muito abordada nas inúmeras reuniões sobre o tema (SHIPPER, 2009).

Todas essas questões envolvem três escolas de pensamento: os limitacionistas, os adaptacionistas e os realistas ${ }^{1}$. Os primeiros são aqueles que acreditam que a redução das emissões de gases de efeito estufa deve ser o foco das ações em resposta às mudanças climáticas; os adaptacionistas acreditam na força da seleção natural e no poder do mercado, o que garantiria que a sociedade se ajustaria as mudanças, não necessitando de ações concretas para se atingir tal ajuste; e os realistas, escola mais recente, para os quais a mudança do clima é um fato, reconhecendo as incertezas sobre seus possíveis impactos e que as medidas de adaptação são reais e cruciais opções de resposta para essas mudanças, devendo ser associadas às medidas de mitigação em vigor (SCHIPPER, 2009).

Para Schipper (2009), tanto a escola limitacionista quanto a adaptacionista fizeram com que as pesquisas sobre adaptação não avançassem até a década de 2000 , período em que emerge a escola realista, sendo a única a ter o posicionamento de que as medidas de adaptação e mitigação são

\footnotetext{
${ }^{1}$ Existem outros termos para nomear essas escolas. Para Kates (1997), por exemplo, as duas primeiras escolas chamam-se prevencionistas e adaptacionistas, ambas com o mesmo significado daquelas citadas por Schipper (2009).
} 
complementares, rompendo com o pensamento dicotômico anterior defendido pelas demais escolas. Além disso, as escolas anteriores à realista não reconheciam a vulnerabilidade e a incapacidade dos países em desenvolvimento de se adaptarem às mudanças no clima, situação que se agrava à medida que alguns países já começam a sentir possíveis resultados dessas mudanças em seus territórios, como as pequenas ilhas dos Oceanos Pacífico e Índico. Atualmente, as mudanças climáticas não são mais tidas como algo distante, mas sim como uma realidade, sendo reconhecida a necessidade de outras formas de resposta, rompendo com a esperança de que a mitigação, por si só, conseguiria atingir resultados satisfatórios sem a necessidade de medidas adaptativas.

A adaptação emergiu na década de 2000 como alternativa à mitigação devido a alguns fatores, como explica Pelling (2003): um deles é a ausência do maior poluidor do mundo nos acordos internacionais de redução de emissão dos gases de efeito estufa - os EUA - fazendo com que a mitigação perdesse força no cenário global, impulsionando as discussões de adaptação em nível nacional e local. Para o autor, os que já estão sofrendo os efeitos das mudanças ambientais são os que terão que agir, já que os maiores responsáveis por essas mudanças não cooperam de maneira significativa para reduzir suas emissões, o que é uma boa notícia para os países mais desenvolvidos da América do Norte e Europa Ocidental, que se eximem de responsabilidades. Países como as Maldivas, com baixo poder de mitigação, mas que correm grande risco devido às mudanças no clima, podem sofrer resultados catastróficos, caso não se adaptem, em detrimento das políticas de mitigação.

Schipper (2009) argumenta que as discussões sobre adaptação também emergiram na década de 2000 após o fracasso da 6a Conferência do Clima (COP6: The Netherlands, 2000) em definir as diretrizes para o Protocolo de Kyoto (que só se consolidaram em 2005, com a adoção do Acordo de Marrakesh), quando os países em desenvolvimento perceberam que atingir os objetivos do protocolo representaria um grande desafio de ordem prática e política e que os mecanismos propostos seriam implementados muito mais lentamente do que o esperado.

No que tange a UNFCCC, logo após a divulgação do terceiro relatório do IPCC (2001) foi criada uma agenda para discussão em adaptação e, em 2004, foi adotado um grupo de trabalho para a temática, o que foi considerado de grande relevância para a área. Em paralelo estava sendo discutido, desde a COP7 (2001), o Acordo de Marrakesh, que foi adotado em 2005 e definiu as regras do Protocolo de Kyoto, além de criar dois importantes fundos para promover adaptação: o Fundo Especial para Mudança Climática e o Fundo para os Países Menos Desenvolvidos (BURTON et al., 2009).

Além disso, na COP10 (2004) foi adotado o "Buenos Aires Programme of Work on Adaptation and Response Measures", tendo seus objetivos e escopo especificados na COP11 (2005), entrando em vigor na COP13 (2007) pelo "Bali Roadmap". Esse programa procurava articular alianças entre os países do norte e do sul para promover a adaptação nos países em desenvolvimento (GRASSO, 2010).

O próprio IPCC, seguindo a linha da UNFCCC, em seu em seu quarto relatório, em 2007, já demonstrava o rompimento com a visão anterior mencionando que a mitigação e a adaptação não funcionariam sozinhas, sendo ações complementares e que, unidas, poderiam reduzir fortemente os riscos das 
mudanças climáticas (IPCC, 2007). O estabelecimento de diretrizes e pesquisas mais aprofundadas sobre a adaptação também se tornou necessário ao se compreender que as crises econômicas que afligem os países em determinados momentos impactam diretamente numa menor atuação nas questões ambientais nesses períodos, necessitando regras a serem seguidas que não sejam impactadas em períodos de crises - com afrouxamento de financiamentos para pesquisas e medidas adaptativas - que podem retardar a atuação dos países nessa área.

Desde então o foco em adaptação como responsabilidade política floresceu e projetos nesse sentido se multiplicaram em todo o globo. Essa explosão de ações adaptativas também se reflete no campo científico, que acompanhou essa tendência, intensificando as pesquisas e publicações, fato que pode ser verificado pelo estudo de caso analisado neste artigo.

\section{EVOLUÇÃO DA PESQUISA EM ADAPTAÇÃO}

Como foi observado, há uma nova tendência em pesquisas sobre adaptação, que emergiu na primeira metade da década de 2000. Essa tendência se deve a uma série de fatores, já discutidos, que repercutiram no campo científico e resultaram em um número cada vez maior de artigos publicados em uma série de revistas da área.

Para exemplificar essa evolução das pesquisas em adaptação, foi escolhida uma revista de impacto do assunto, avaliando seus artigos em dois momentos: primeiro envolvendo o período anterior e durante as discussões do Acordo de Marrakesh, de 1999 a 2003, antes de ser adotado em 2005, e segundo, após sua adoção, já com ambiente favorável às discussões sobre adaptação, de 2009 a 2013. A escolha desses dois períodos se deu para elucidar como o campo científico se comportou entre esses dois momentos de análise, para identificar se houve mudança real nas pesquisas em paralelo às discussões do tema nas diversas reuniões e acordos internacionais realizados na última década.

A revista escolhida para o estudo de caso foi a Mitigation and Adaptation Strategies for Global Change (ISSN: 1381-2386, versão impressa; 1573-1596, versão online), tendo sido escolhida pelo caráter interdisciplinar de seus artigos e pela relevância de seu conteúdo. O fato de haver publicações online disponíveis em ambos os períodos selecionados para o estudo foi um elemento facilitador da análise.

A revista conta com um corpo editorial de 35 pesquisadores dos cinco continentes, porém com maior representatividade de países europeus e da América do Norte, sendo o editor chefe Robert K. Dixon, do Office of Energy Efficiency and Renewable Energy, U.S. Department of Energy, Washington, DC, EUA. Sua editora é a Springer Netherlands e teve seu primeiro volume publicado em 1996, possuindo atualmente um total de 21 volumes publicados com mais de mil artigos, com fator de impacto do Journal Citation Reports de 3.085.

Essa revista aborda ampla gama de assuntos relacionados ao meio ambiente, à economia e sobre energia, englobando tópicos como mudança climática global; destruição da camada de ozônio; extinção de espécies; desflorestamento; desertificação; mudança do nível do mar; entre vários outros. 
Ela surgiu a partir da necessidade de garantir a sustentabilidade da biosfera para todas as formas de vida frente aos perigos eminentes das mudanças do clima, transmitindo opções de resposta a esses perigos por mitigação e adaptação, fornecendo um fórum para conceituação, análise crítica e debate dessas questões.

\subsection{ANÁLISE DA REVISTA MITIGATION AND ADAPTATION STRATEGIES FOR GLOBAL CHANGE}

Foram analisados todos os 351 artigos publicados pela revista Mitigation and Adaptation Strategies for Global Change durante os períodos de 1999-2003 e 2009-2013. A primeira tarefa foi identificar os artigos publicados que faziam referência ao tema de adaptação, separando-os dos demais, como mitigação. Do total de 351 artigos, 141 abordavam a questão de adaptação, enquanto os demais remetiam a outros assuntos e, após essa divisão, foram selecionados os temas de cada publicação, sendo que os artigos poderiam abordar uma série de tópicos de uma vez. Os temas foram agrupados e separados em categorias específicas para melhor compreensão dos assuntos discutidos, sendo eles: agricultura e pecuária; conceitos de adaptação; aspectos sociais; zona costeira e elevação do nível do mar; indústria e aspectos técnicos; custos e financiamento; água; aspectos políticos e governança; eventos extremos (secas, inundações etc.); energia e carbono; modelos; ecologia; planos e programas; e florestas.

No primeiro período, de 1999 a 2003, de um total de 103 artigos publicados pela revista, 23 tinham foco em adaptação, enquanto 80 abordavam outros assuntos, sendo uma diferença de 57 artigos. Desses 23 artigos, 13 foram publicados em 1999, 11 dos quais apenas na terceira edição do ano, que correspondeu a um caderno especial específico sobre adaptação. Caso contrário, o número de artigos publicados sobre adaptação nesse período seria bem menor, já que nos anos seguintes a tendência era de quase nenhuma publicação nesse tópico: o ano de 2000 com uma publicação; 2001 com nenhuma; 2002 com seis; e 2003 com três (Figura 2). Isso evidencia que apesar do esforço da revista com a publicação de um caderno especial sobre adaptação, a comunidade científica não seguiu priorizando esse foco.

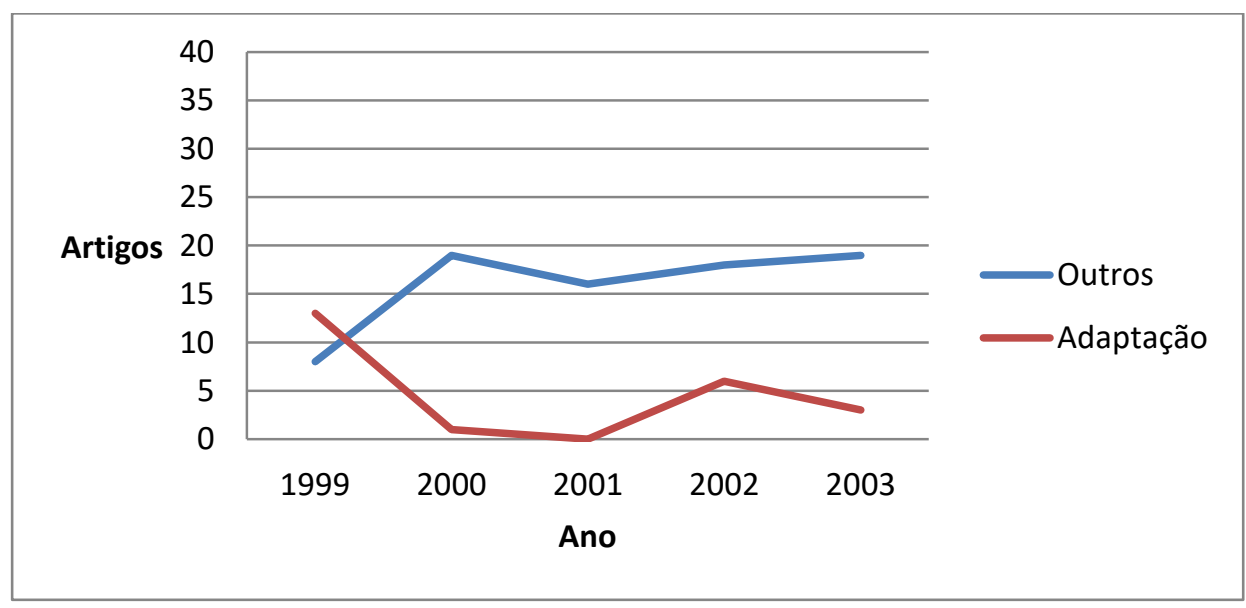

Figura 2 - Número de artigos entre 1999-2003; Organizado por Moreira, F. A. com base em Mitigation and Adaptation Strategies for Global Change. 
Já no segundo período, de 2009-2013, de um total de 248 artigos publicados, 118 abordavam a temática da adaptação, enquanto 130 focavam outros assuntos: uma diferença de apenas 12 artigos, bem menor do que a apresentada no primeiro período, ainda mais ao considerar o número total de publicações em cada um deles. A tendência nesse período, diferentemente do primeiro, foi de haver cada vez mais publicações sobre adaptação, às vezes até ultrapassando as de outros temas durante o ano: em 2009 foram 16 publicações, contra 25 de outros assuntos; em 2010 foram 25 contra 19; em 2011 foram 25 contra 22; em 2012 foram 26 contra 27; e em 2013 foram 26 contra 37 (Figura 3).

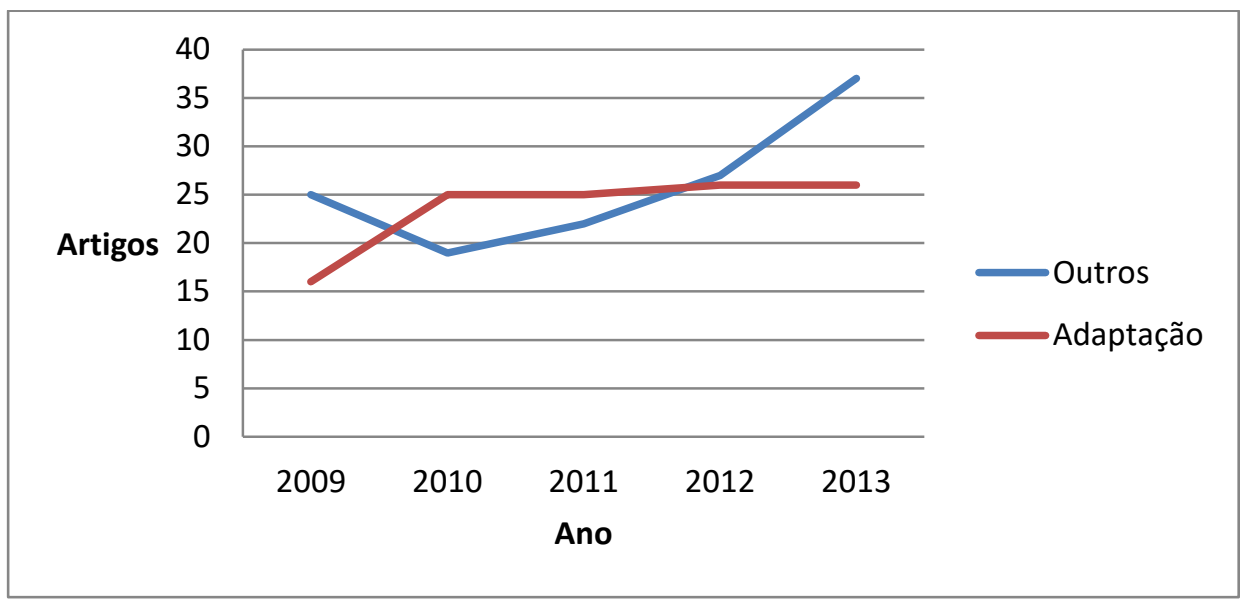

Figura 3 - Número de artigos entre 2009-2013; Organizado por Moreira, F. A. com base em Mitigation and Adaptation Strategies for Global Change.

Uma primeira observação a ser feita é a diferença entre os números de publicações sobre adaptação e sobre os demais assuntos. No primeiro período, excetuando-se o ano de 1999 - que foi peculiar devido à publicação do caderno especial sobre adaptação - nota-se a prevalência bem acentuada dos demais assuntos sobre adaptação, enquanto no segundo período pode-se observar que a contribuição dos demais temas e de análises sobre adaptação já se encontram bem próximas. Isso reflete como os dois períodos se diferenciam no foco que era dado pela revista, representando bem a evolução das pesquisas sobre adaptação em relação àquelas sobre mitigação no decorrer da década de 2000, conforme Figura 4 da comparação do número de artigos por tema para cada período. 


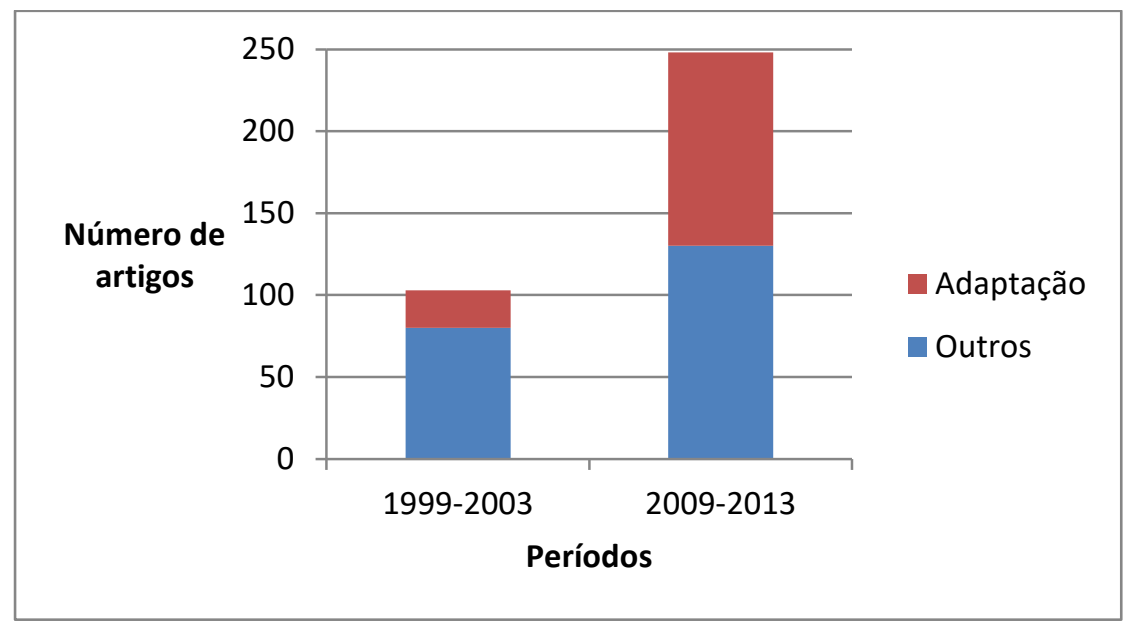

Figura 4 - Total de artigos publicados por tema nos períodos de 1999-2003 e 2009-2013 Organizado por Moreira, F. A. com base em Mitigation and Adaptation Strategies for Global Change.

Conforme destacado, no primeiro período foram publicados 23 artigos sobre adaptação, sendo que cada um deles abordou uma série de temas distintos: agricultura e pecuária (cinco vezes), conceitos de adaptação (quatro vezes), aspectos sociais (quatro vezes), zona costeira e elevação do nível do mar (três vezes), indústria e aspectos técnicos (três vezes), custos e financiamento (uma vez), água (uma vez), aspectos políticos e governança (uma vez), eventos extremos (secas, inundações etc. - uma vez), energia e carbono (uma vez), modelos (uma vez), e ecologia, planos e programas e florestas não foram abordados nenhuma vez (Figura 5)

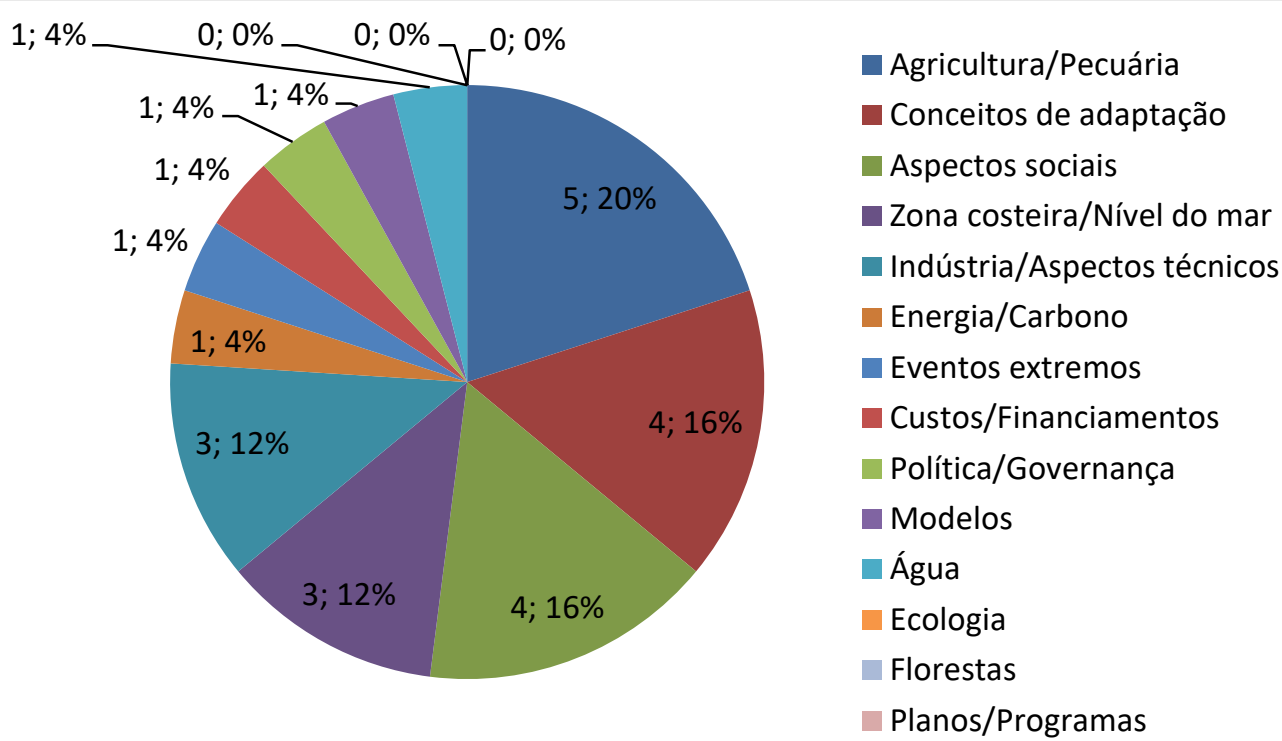

Figura 5 - Temas no período 1999-2003; Organizado por Moreira, F. A. com base em Mitigation and Adaptation Strategies for Global Change 
No segundo período, com 118 artigos publicados, a divisão dos temas foi: agricultura e pecuária (29), aspectos políticos e governança (18), custos e financiamento (18), zona costeira e elevação do nível do mar (13), eventos extremos (secas, inundações etc. - 13), florestas (12), aspectos sociais (11), energia e carbono (9), conceitos de adaptação (8), planos e programas (8), modelos (7), água (6), indústria e aspectos técnicos (4), ecologia (3), conforme Figura 6.

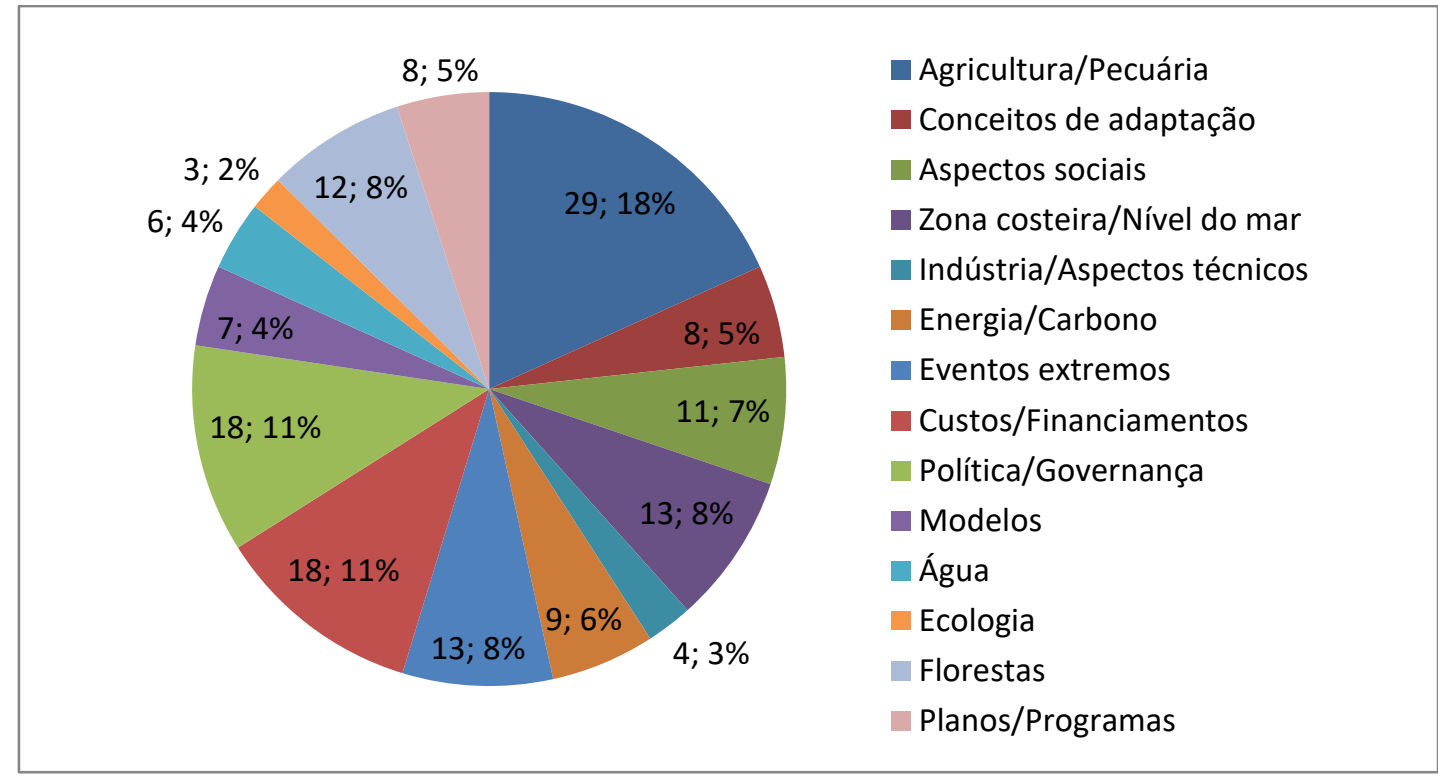

Figura 6 - Temas no período 2009-2013; Organizado por Moreira, F. A. com base em Mitigation and Adaptation Strategies for Global Change.

A análise das Figuras 5 e 6 permite observar quais os temas principais abordados pelos artigos no decorrer do tempo entre os dois períodos e qual o foco dado pela revista às pesquisas aceitas para publicação. No primeiro período o tema mais recorrente foi a agropecuária, com cinco artigos, demonstrando preocupação antiga sobre os possíveis efeitos das mudanças no clima para as plantações, principalmente, que se intensifica e se mantém como principal questão no segundo período, com 29 artigos sobre o assunto, com exemplos de artigos como: "An evaluation of adaptation options for climate change impacts on agriculture in kazakhstan" (MIZINA et al., 1999) e "Adaptation to climate change: changes in farmland use and stocking rate in the U.S." (MU et al., 2013).

Mesmo havendo essa preocupação do setor agropecuário em se adaptar às mudanças do clima, o tema da adaptação era pouco abordado e compreendido até o primeiro período, fato que se evidencia pelo segundo tema mais abordado nos anos de 1999 a 2003: a conceituação de adaptação, com os exemplos de artigos: "A framework and key questions for adapting to climate variability and change" (WHEATON, MACIVER, 1999) e "The science of adaptation: a framework for assessment" (SMIT et al., 1999).

Até então havia ainda pouco conhecimento sobre o assunto, necessitando de mais pesquisa no campo, e é justamente devido a esse fato que questões 
como financiamento/custos e política/governança tiveram pouca atenção nas publicações desse período. Os temas de maior destaque: conceituação; aspectos sociais; zonas costeiras e elevação do nível do mar; e aspectos técnicos indicam o início das discussões acerca do tema, que necessitavam da formação de um arcabouço de compreensão melhor desenvolvido para apenas depois serem discutidos os demais aspectos.

Essa questão se desdobra no decorrer da década de 2000 culminando, no segundo período, em uma abordagem maior dos demais temas sobre adaptação. Como se observa no segundo período, além da questão da agropecuária, que se mantêm como tema mais discutido com 29 artigos, outros temas importantes tiveram destaque nas publicações, como política/governança, com 18 artigos (ex.: "Pursuing an integrated development and climate policy framework in Africa: options for mainstreaming" (CHUKU, 2010); "The European Commission White Paper on adaptation: appraising its strategic success as an instrument of soft law" (DREYFUS, PATT, 2012)), e financiamento e custos, com 18 artigos (ex.: "Adaptation investments: a resource allocation framework" (BARR et al., 2010) e "Estimated effects of climate change on flood vulnerability of U.S. bridges" (WRIGHT et al., 2012)), deixando para trás os temas de conceituação, aspectos sociais e técnicos.

Pela Figura 7 pode-se observar o crescimento em número de artigos entre os dois períodos, demonstrando justamente essa tendência em se debater aspectos de financiamento e de política, deixando para trás as pesquisas conceituais e técnicas, embora o tema de agropecuária se mantenha como tema mais discutido. Porém, quando se observa a Figura 8 , sobre o crescimento relativo de cada tema entre os dois períodos, vários têm um crescimento maior do que o de agropecuária, como o de governança/política, financiamento/custos e eventos extremos.

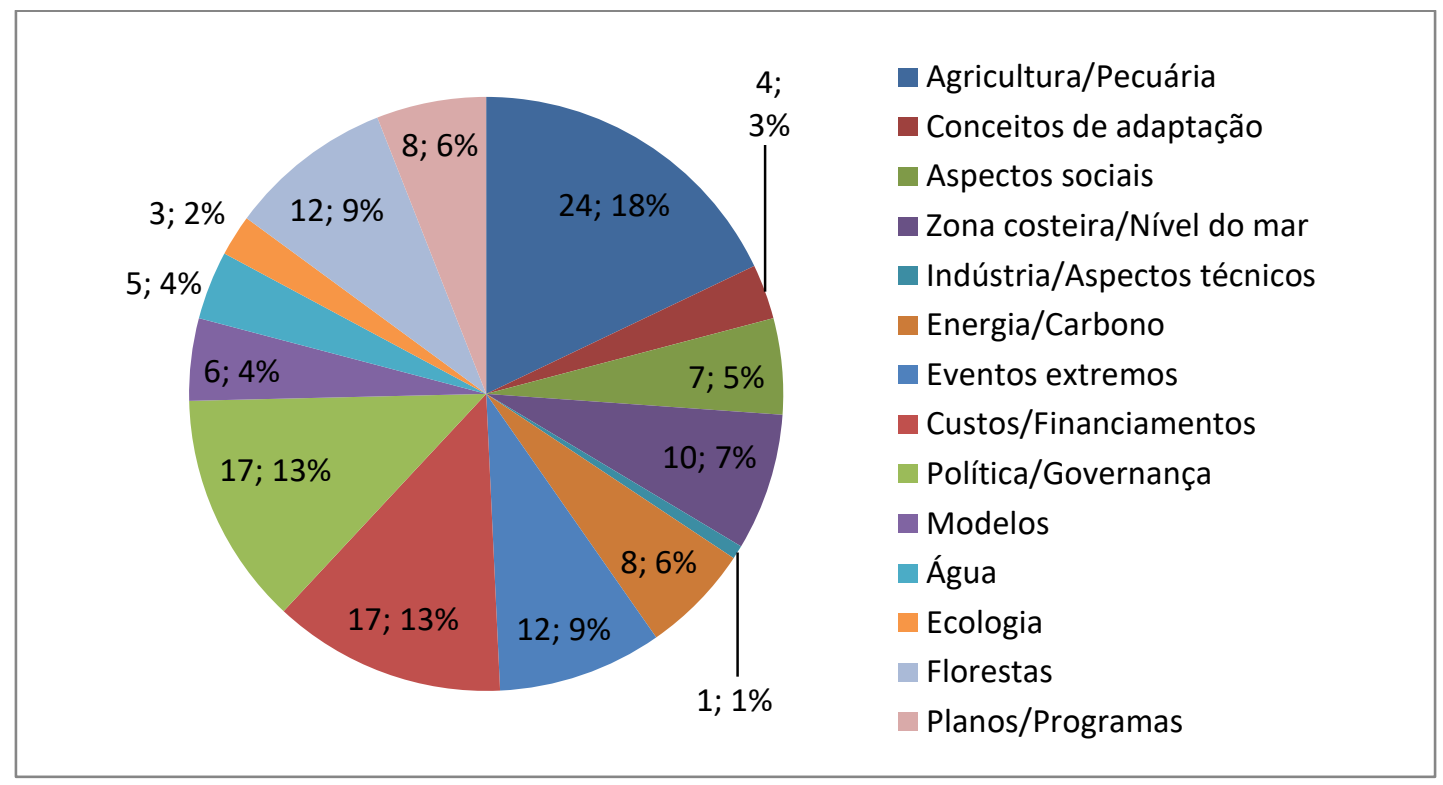

Figura 7 - Crescimento dos temas nos artigos entre os dois períodos (1999-2003 e 2009-2013); Organizado por Moreira, F. A. com base em Mitigation and Adaptation Strategies for Global Change. 


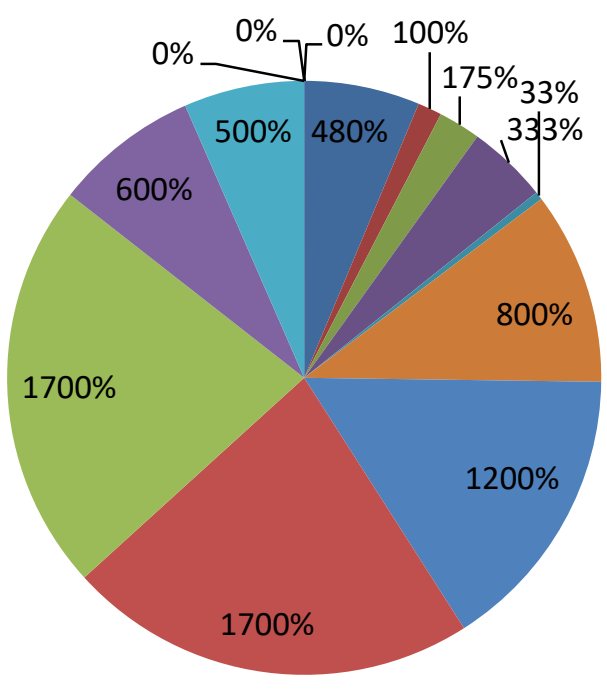

- Agricultura/Pecuária

- Conceitos de adaptação

Aspectos sociais

- Zona costeira/Nível do mar

- Indústria/Aspectos técnicos

- Energia/Carbono

- Eventos extremos

- Custos/Financiamentos

- Política/Governança

- Modelos

- Água

Ecologia

Florestas

- Planos/Programas

Figura 8 - Crescimento relativo dos temas entre 1999-2003 e 2009-2013; Organizado por Moreira, F. A. com base em Mitigation and Adaptation Strategies for Global Change.

Os eventos extremos também têm cada vez maior destaque no campo científico, de acordo com as publicações apresentadas pela revista. Entre os exemplos de artigos que abordam os eventos extremos podem ser destacados: "Improving adaptive capacity and resilience in Bhutan" (MEENAWAT, SOVACOOL, 2011), que fala dos riscos de inundações e escorregamentos de solo; "Coastal livelihood and physical infrastructure in Bangladesh after cyclone Aila" (MALLICK et al., 2011); entre outros.

Enquanto no primeiro período houve apenas um artigo sobre os eventos extremos, no segundo período foram publicados 13 artigos, estando entre os cinco temas mais abordados pela revista. Essa tendência pode ter ocorrido pelo fato de na década de 2000 vários episódios de eventos extremos terem impactado as populações em todo o globo, representando grande desafio para os países em adaptar seus territórios para reduzirem suas vulnerabilidades contra eventos futuro, já que existe uma série de previsões em que as mudanças climáticas podem influenciar em episódios cada vez mais concentrados no tempo, porém, com impactos mais severos.

Considerando os dois períodos, os temas mais abordados foram: agricultura e pecuária (34), aspectos políticos e governança (19), custos e financiamento (19), zona costeira e elevação do nível do mar (16), aspectos sociais (15), eventos extremos (secas, inundações, etc.- 14 vezes), conceitos de adaptação (12), florestas (12) ${ }^{2}$, energia e carbono (10), planos e programas (8), modelos (8), água (7), indústria e aspectos técnicos (7), ecologia (3), conforme Figura 9.

\footnotetext{
${ }^{2} \mathrm{O}$ caso do número de artigos sobre florestas é peculiar já que houve um caderno especial, em 2011, com cinco artigos apenas sobre esse assunto, de uma vez, o que deu destaque a esse tema no quadro geral, fazendo, inclusive, com que esse assunto fosse separado como um dos temas centrais nesse artigo.
} 
A Figura 9 demonstra que existe grande preocupação, já apresentada desde o primeiro período, com os impactos possíveis para a agropecuária mundial, que pode vir a sofrer grandes perdas de safras e exige mudanças de técnicas de plantio e adaptações genéticas para se continuar produzindo os alimentos em todo o mundo; caso contrário, podem ocorrer problemas de ordem econômica, social e ambiental.

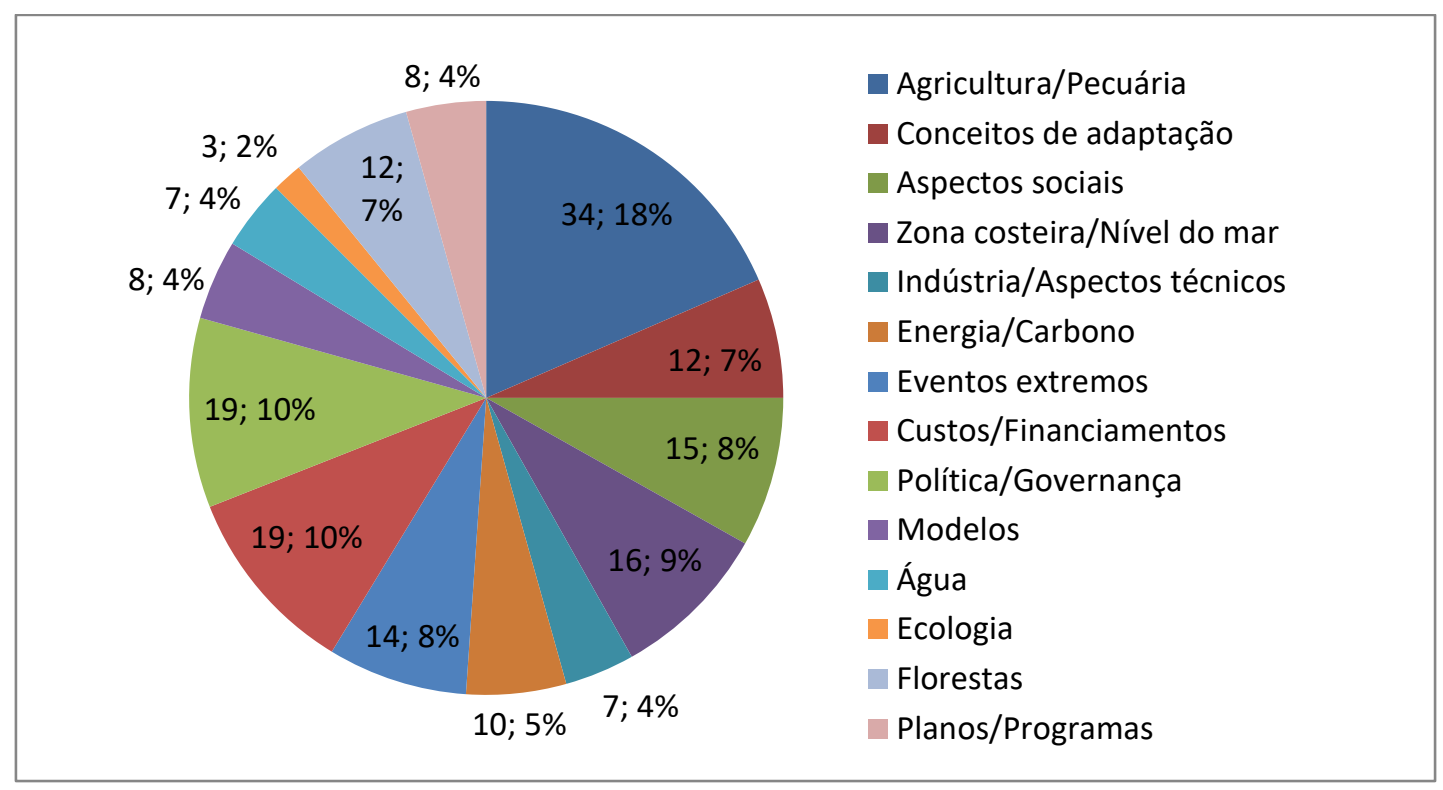

Figura 9 - Total de artigos por tema entre 1999-2003 e 2009-2013; Organizado por Moreira, F. A. com base em Mitigation and Adaptation Strategies for Global Change.

Além disso, o fato de que a questão da política/governança e do financiamento/custos foram os dois temas mais discutidos após a agropecuária demonstra a preocupação em como os países devem se organizar para criar um ambiente favorável à adaptação, por meio de reuniões e acordos internacionais e como (e quem) financiar as medidas adaptativas. Sobre isso, no item anterior foi mencionado como os países em desenvolvimento, principalmente aqueles com menor capacidade de mitigar suas emissões de gases de efeito estufa, poderão ser os primeiros a sofrer os impactos das mudanças no clima, não tendo condições financeiras e técnicas para se adaptar, necessitando de ajuda externa para tal. Ao mesmo tempo, os países de primeiro mundo ainda mantêm, em geral, o discurso sobre as responsabilidades das mudanças climáticas, tentando se eximir dessa responsabilidade para evitar gastos com adaptação em outros países mais pobres.

A questão da adaptação das zonas costeiras e, em paralelo, da elevação do nível do mar, vem logo a seguir, com 16 artigos (sendo três do primeiro período e 13 do segundo), o que atesta a preocupação crescente com essas áreas que podem vir a sofrer grande impacto, de ordem econômica, social e ambiental, e chama cada vez mais a atenção dos pesquisadores e de governantes de diversos países, com exemplos de artigos: "Coastal adaptation to climate change: can the IPCC technical guidelines be applied?" (KLEIN et al., 
1999) e "Coastal flooding, climate change and environmental justice: identifying obstacles and incentives for adaptation in two metropolitan Boston Massachusetts communities" (DOUGLAS et al., 2012).

Conforme a Tabela 1, os artigos que apresentavam algum trabalho sobre adaptação aplicado em algum país ou região específico tiveram maior proeminência no continente asiático, com 33 artigos, seguido pela África, com 22, América, com 16, Europa, com 10, e Oceania, com três (totalizando 84 artigos). Os países com mais trabalhos de adaptação aplicados a seus territórios foram: a Índia, com 11 artigos, os EUA, com sete, e o Canadá, com seis. Embora tal observação não reflita, necessariamente, a distribuição dos artigos de adaptação pelo mundo por todas as revistas existentes, é interessante observar que não existe foco específico apenas em países centrais, mas essa revista recebe contribuição de diversas áreas do globo, possibilitando que o conhecimento de países não centrais também possa ser difundido e, assim, novas percepções e possibilidades possam ser estabelecidas entre os mais diversos países.

Entretanto, embora existam artigos abordando questões de diferentes nacionalidades, nem sempre o conhecimento sobre elas é gerado pelos próprios países dos quais os artigos tratam: das 84 pesquisas identificadas abordando algum país ou região, 42 possuem pesquisadores de mais de um país entre seus autores, e grande parte desses receberam algum tipo de financiamento proveniente de alguma organização ou instituição de países de primeiro mundo. Isso demonstra a importância de convênios internacionais entre países desenvolvidos e em desenvolvimento, com equipes interdisciplinares com diversas abordagens, contribuindo para os estudos em locais que não necessariamente conseguem financiar tais trabalhos.

Tabela 1- Número de artigos com pesquisas aplicadas sobre adaptação por continente

\begin{tabular}{cc}
\hline Continente & $\mathbf{N}^{\mathbf{0}}$ de artigos \\
\hline Ásia & 33 \\
África & 22 \\
América & 16 \\
Europa & 10 \\
Oceania & 3 \\
Total & 84 \\
\hline
\end{tabular}

Organizado por Moreira, F. A. com base em Mitigation and Adaptation Strategies for Global Change.

Dentre os demais trabalhos que abordam algum aspecto de adaptação em algum país ou região específico e que não têm participação de países estrangeiros, 27 são trabalhos de países desenvolvidos e 15 são de países em desenvolvimento (inclusive seus financiamentos para pesquisa). Apesar de maior número de pesquisas publicadas por países desenvolvidos, observa-se que também existem nações preocupadas com a questão de adaptação às mudanças no clima e que conseguem diversas formas de financiamento de seus 
trabalhos locais, sem participação de outros países. Todavia, até então o que predomina são as pesquisas em parceria, preponderando aquelas com verba proveniente dos países desenvolvidos, demonstrando a importância dessas relações para o enfrentamento dos possíveis efeitos causados pelas mudanças no clima nos países em desenvolvimento, que sempre possuem capacidade técnica e financeira para desenvolver suas pesquisas no campo. Não obstante, é interessante observar que se estudos conjuntos oferecem enormes vantagens, estudos endógenos podem revelar uma visão diferente, provendo novas possibilidades.

As equipes interdisciplinares que compõem o corpo de autores das pesquisas publicadas pela revista são das mais diversas áreas, como engenharia, políticas públicas, agricultura, climatologia, economia, geografia, química, meio-ambiente, direito, desenvolvimento sustentável, tecnologia, saúde pública, desastres naturais, turismo, ciências do solo, da água, das florestas, entre outros, o que denota a pluralidade das áreas e questões que influenciam na adaptação dos países para os efeitos das mudanças do clima. Além disso, algumas parcerias privadas aparecem como participantes das pesquisas publicadas pela revista, seja com membros no corpo de pesquisadores, seja com financiamento da pesquisa, com exemplos da Starbucks Coffee Company, de Seattle, EUA; Chevron Services Company, EUA; Stratus Consulting Inc., EUA. Os financiamentos das pesquisas são oriundos de diversas fontes, como bancos centrais, instituições de pesquisa, empresas privadas, agências internacionais, tendo como destaque o financiamento oferecido por instituições dos EUA, da União Europeia e do Banco Mundial.

Também é interessante observar a participação do corpo editorial nas publicações da revista: para o primeiro período analisado seis artigos das instituições dos membros do corpo editorial foram publicados, representando $26 \%$ do total de artigos para o período, enquanto no segundo período foram 22 artigos publicados provenientes das instituições dos membros do corpo editorial, representando uma participação de $18 \%$ do total de artigos do período.

\section{CONSIDERAÇÕES FINAIS}

Como se pôde observar nesse artigo, as discussões sobre as mudanças climáticas em todo o globo sofreram mudanças no decorrer da década de 2000, agregando alguns tópicos até então não abordados com muito destaque. A temática da adaptação, principalmente, emergiu a partir de meados dessa década devido a uma série de fatores, destacando a necessidade em se aplicar medidas adaptativas no presente, já que, pela inércia do sistema climático que mantém os gases de efeito estufa já emitidos em suspensão por, aproximadamente, 70 anos, os resultados das mudanças climáticas continuarão atuando até que essas emissões sejam estabilizadas e o aquecimento global controlado.

Alguns dos acontecimentos que fizeram o tema de adaptação emergir foram as medidas tomadas pela UNFCCC, como a criação e adoção do Acordo de Marrakesh, de 2001 a 2005, criando fundos para as políticas adaptativas para os países interessados; e o "Bali Roadmap", em 2007, que buscou articular alianças entre os países do norte e do sul para promover a adaptação nos países em desenvolvimento; além de outras ações fora do Quadro das Nações Unidas, 
como a definição e maior destaque dado à adaptação no quarto relatório do IPCC, em 2007.

Essa mudança de visão voltada unicamente ao tópico da redução das emissões dos gases de efeito estufa se refletiu nas pesquisas científicas, caso observado pela análise bibliométrica, já apresentada pelo $5^{\circ}$ relatório científico do IPCC, em 2014, e analisado por meio de uma revista específica nesse artigo. Foi possível observar com a análise da revista Mitigation and Adaptation Strategies for Global Chang, entre os períodos de 1999-2003 e 2009-2013, a evolução das pesquisas em adaptação, em paralelo às de mitigação, tendo maior destaque no segundo período abordado do que havia no primeiro.

Enquanto no primeiro período as pesquisas em adaptação tinham pouco destaque na revista, as pesquisas em mitigação já avançavam em ritmo maior. Nesse período, as pesquisas sobre adaptação davam maior destaque à questão dos impactos possíveis para a agropecuária, assim como aos aspectos conceituais e sociais, denotando início para os estudos desse campo que careciam de base científica para, posteriormente, avançarem em outros temas.

No segundo período os temas principais abordados se modificaram, dando cada vez maior destaque às questões de governança, tendo caráter político e de financiamento, já que a base científica já havia sido mais bem explorada e agora havia necessidade de se definirem os acordos internacionais para se incentivar as medidas adaptativas e como financiar tais medidas.

Sendo assim, pode-se considerar que a preocupação com os efeitos das mudanças climáticas nos territórios dos países no curto prazo passou a ser uma preocupação real em todo o globo, estimulando o avanço das pesquisas científicas sobre a adaptação contra esses efeitos. Há, atualmente, maior percepção de que o risco é iminente, principalmente para vários países em desenvolvimento, que carecem de infraestrutura e condições financeiras e técnicas para prevenir contra esses eventos; no entanto, alguns percalços ainda persistem, principalmente no que se refere ao apoio (financeiro e técnico) dado pelos países desenvolvidos para esses países emergentes, passando pela questão da responsabilização pelas mudanças do clima.

Em relação às pesquisas, foi observada a relevância das parcerias internacionais para 0 desenvolvimento de pesquisas nos países em desenvolvimento, com metade das publicações de estudos de caso realizadas graças a esses acordos e financiamentos externos, ou seja: os países não centrais carecem de recursos próprios e o financiamento externo proveniente de instituições de pesquisa, organizações internacionais, ou mesmo de empresas privadas, é cada vez mais crucial para o desenvolvimento da capacidade adaptativa nesses países.

Por fim, há de se destacar que, embora a questão da adaptação tenha emergido na década passada, não se devem deixar de lado as ações de mitigação tomadas até então, pois as duas questões devem ser trabalhadas em conjunto, havendo medidas preventivas no período atual, mas sem perder o controle das emissões de gases de efeito estufa, que contribui para frear o aquecimento global futuro e, consequentemente, faz com que haja menor necessidade de se adaptar em longo prazo. Nesse sentido, Grasso (2010) afirma que mitigação e adaptação estão inevitavelmente correlacionadas e integrá-las 
nos processos de tomada de decisão é muito útil para se produzir diversos benefícios e soluções "win-win", não apenas no âmbito da política.

Além disso, conforme Ojima (2009), muitas vezes no planejamento de investimentos de médio e longo prazo, principalmente em infraestrutura, considerar as projeções de mudanças ambientais globais hoje tem um custo muito pequeno se comparado aos custos de remediação, o que se tornou o pensamento em voga nas discussões entre os países desenvolvidos.

\section{AGRADECIMENTOS}

Pesquisa realizada com financiamento da Fundação de Amparo à Pesquisa do Estado de São Paulo (Proc. Fapesp 2014/14598-8), vinculada ao Projeto: "METROPOLE: An Integrated Framework to Analyze Local Decision Making and Adaptive Capacity to Large-Scale Environmental Change: Community Case Studies in Brazil, UK and the US" (Forum Belmont, Proc. G8MUREFU3 2201-040, Proc. Fapesp 2012/51876-0).

\section{REFERÊNCIAS BIBLIOGRÁFICAS}

ALAM, M. M. et al. 'Paddy farmers' adaptation practices to climatic vulnerabilities in Malaysia. Mitigation and Adaptation Strategies for Global Change. 17:415423, 2012.

BARR, R. et al. Adaptation investments: a resource allocation framework. Mitigation and Adaptation Strategies for Global Change. 15: 843-858, 2010.

BURTON, I. et al. From Impacts Assessment to Adaptation Priorities: The Shaping of Adaptation Policy. In: SCHIPPER, E. L. F.; BURTON, I. (Orgs.) The earthscan reader on adaptation to climate change. Earthscan, London, 2009.

CHUKU, C. A. Pursuing an integrated development and climate policy framework in Africa: options for mainstreaming. Mitigation and Adaptation Strategies for Global Change. 15: 41-52, 2010.

DOUGLAS, E. M. et al. Coastal flooding, climate change and environmental justice: identifying obstacles and incentives for adaptation in two metropolitan Boston Massachusetts communities. Mitigation and Adaptation Strategies for Global Change. 17: 537-562, 2012.

DREYFUS, M.; PATT, A. The European Commission White Paper on adaptation: appraising its strategic success as an instrument of soft law. Mitigation and Adaptation Strategies for Global Change. 17: 849-863, 2012.

FERREIRA, L. C. A questão ambiental: Sustentabilidade e políticas públicas no Brasil. Boitempo, São Paulo, 2003.

GRASSO, M. Justice in funding adaptation under the international climate change regime. Springer, New York, 2010.

HELLER, N. E.; ZAVALETA, E. S. Biodiversity management in the face of climate change: A review of 22 years of recommendations. Biological Conservation. 142: $14-32,2009$. 
IPCC. Fourth Assessment Report: Climate Change. Working Group II: Impacts, Adaptation and Vulnerability. 2007. [Online] Disponível em: <https://www.ipcc.ch/publications_and_data/ar4/wg2/en/ch17s17-2-2.html> Acessado em: 6 de junho de 2016.

IPCC. Intergovernmental Panel on Climate Change. Climate change: Synthesis Report - Summary for Policymakers. Intergovernmental Panel on Climate Change, Geneva, 2007.

IPCC. Intergovernmental Panel on Climate Change. Climate Change 2014: Impacts, Adaptation, and Vulnerability. Cambridge University Press, Cambridge, United Kingdom and New York, 2014.

KATES, R. W. Impacts, adaptations and mitigation - climate change 1995. In: WATSON, R. T. et al. (Orgs.) Environment. 39: no 9: 29-33, 1997.

KLEIN, R. J. T. et al. Coastal adaptation to climate change: can the IPCC technical guidelines be applied? Mitigation and Adaptation Strategies for Global Change. 4: 239-252, 1999.

MALLICK, B.; KHAN, K. R.; VOGT, J. Coastal livelihood and physical infrastructure in Bangladesh after cyclone Aila. Mitigation and Adaptation Strategies for Global Change. 16: 629-648, 2011.

MEENAWAT, H.; SOVACOOL, B. K. Improving adaptive capacity and resilience in Bhutan. Mitigation and Adaptation Strategies for Global Change. 16: 515-533, 2011.

MIMURA, N. Scope and roles of adaptation to climate change. In: SUMI, A. et al. (Orgs.) Adaptation and Mitigation Strategies for Climate Change. Springer, New York, 2010.

MITIGATION AND ADAPTATION STRATEGIES FOR GLOBAL CHANGE. The Netherland: Springer, vol. 4-8; 14-18. ISSN: 1381-2386, versão impressa; 1573-1596, [Online] Disponível em: <http://link.springer.com/journal/11027> Acessado em: 6 de junho de 2016.

MIZINA, S. V. et al. An evaluation of adaptation options for climate change impacts on agriculture in Kazakhstan. Mitigation and Adaptation Strategies for Global Change. 4: 25-41, 1999.

MU, J. E. et al. Adaptation to climate change: changes in farmland use and stocking rate in the U.S. Mitigation and Adaptation Strategies for Global Change. 18: 713-730, 2013.

OJIMA, R. Perspectivas para a adaptação frente às mudanças ambientais globais no contexto da urbanização brasileira: cenários para os estudos de população. In: HOGAN, D. J.; MARANDOLA Jr., E. (Orgs.) População e mudanças climáticas: Dimensões humanas das mudanças ambientais globais. Núcleo de Estudos de População-Nepo/Unicamp, Campinas; UNFPA, Brasília, 2009.

ORESKES, N. The scientific consensus on climate change. Science. 306:1686, 2004.

ORLOVE, B. Human adaptation to climate change: a review of three historical cases and some general perspective. Environmental Science \& Policy. 8: 589600, 2005. 
PELLING, M. Emerging concerns. In: PELLING, M. (Org.) Natural disasters and development in a globalization world. Routledge, London, 2003.

PELLING, M. Adaptation to climate change. Routledge, London, 2011.

REFSGAARD, J. C. et al. The role of uncertainty in climate change adaptation Strategies - A Danish water management example. Mitigation and Adaptation Strategies for Global Change. 18: 337-359, 2013.

SCHIPPER, E. L. F. Conceptual History of Adaptation in the UNFCCC Process. In: SCHIPPER, E. L. F.; BURTON, I. (Orgs.) The earthscan reader on adaptation to climate change. Earthscan, London, 2009.

SKAGGS, R. H. Climatogy in American Geography. Annals of the Asssociaton of American Geographers. 94: 446-457, 2004.

SMIT, B. et al. The science of adaptation: a framework for assessment. Mitigation and Adaptation Strategies for Global Change. 4: 199-213, 1999.

WHEATON, E. E.; MACIVER, D. C. A framework and key questions for adapting to climate variability and change. Mitigation and Adaptation Strategies for Global Change. 4: 215-225, 1999.

WRIGHT, L. et al. Estimated effects of climate change on flood vulnerability of U.S. bridges. Mitigation and Adaptation Strategies for Global Change. 17: 939955, 2012. 